\title{
Extracellular Volume Quantification using Synthetic Haematocrit Assessed from Native and Post- contrast Longitudinal Relaxation T1 Times of a Blood Pool
}

\section{Lukas Opatril}

1st Department of Internal Medicine and Cardioangiology, International Clinical Research Center, St. Anne's University Hospital, Masaryk University, Faculty of Medicine, Brno

Roman Panovsky ( $\sim$ panovsky@fnusa.cz)

1st Department of Internal Medicine and Cardioangiology, International Clinical Research Center, St. Anne's University Hospital, Masaryk University, Faculty of Medicine, Brno

Jan Machal

International Clinical Research Center, St. Anne's University Hospital, Department of Pathophysiology, Faculty of Medicine, Masaryk University, Brno

\section{Tomas Holecek}

International Clinical Research Center, Department of Medical Imaging, St. Anne's University Hospital, Brno

\section{Lucia Masarova}

1st Department of Internal Medicine and Cardioangiology, International Clinical Research Center, St. Anne's University Hospital, Masaryk University, Faculty of Medicine, Brno

\section{Vera Feitova}

International Clinical Research Center, Department of Medical Imaging, St. Anne's University Hospital, Brno

\section{Vladimir Kincl}

1st Department of Internal Medicine and Cardioangiology, International Clinical Research Center, St. Anne's University Hospital, Masaryk University, Faculty of Medicine, Brno

\section{Marek Hodejovsky}

Masaryk University, Faculty of Medicine, Brno

\section{Lenka Spinarova}

1st Department of Internal Medicine and Cardioangiology, St. Anne's University Hospital, Masaryk University, Faculty of Medicine, Brno

\section{Research Article}

Keywords: Extracellular volume, ECV, Synthetic haematocrit, Cardiovascular magnetic resonance, CMR 
Posted Date: March 11th, 2021

DOl: https://doi.org/10.21203/rs.3.rs-275961/v1

License: (c) (i) This work is licensed under a Creative Commons Attribution 4.0 International License. Read Full License

Version of Record: A version of this preprint was published at BMC Cardiovascular Disorders on July 31st, 2021. See the published version at https://doi.org/10.1186/s12872-021-02179-z. 


\section{Abstract}

\section{Background:}

In terms of cardiovascular magnetic resonance are haematocrit values required for calculation of extracellular volume fraction (ECV). Previously published studies have hypothesized that haematocrit could be calculated from $\mathrm{T} 1$ blood pool relaxation time, however only native $\mathrm{T} 1$ relaxation time values have been used and the resulting formulae had been both in reciprocal and linear proportion.

The aim of the study was to generate a synthetic haematocrit formula from only native relaxation time values first, calculate whether linear or reciprocal model is more precise in haematocrit estimation and then determine whether adding post-contrast values further improve its precision.

\section{Methods:}

One hundred thirty-nine subjects underwent CMR examination. Haematocrit was measured using standard laboratory methods. Afterwards T1 relaxation times before and after the application of a contrast agent were measured and a statistical relationship between these values was calculated.

\section{Results:}

Different linear and reciprocal models were created to estimate the value of synthetic haematocrit and ECV. The highest coefficient of determination was observed in the combined reciprocal model "-0.047 + (779/ blood native) - (11.36/ blood post-contrast)".

\section{Conclusions:}

This study provides more evidence that assessing synthetic haematocrit and synthetic ECV is feasible and statistically most accurate model to use is reciprocal. Adding post-contrast values to the calculation was proved to improve the precision of the formula statistically significantly.

\section{Introduction:}

Cardiovascular magnetic resonance (CMR) provides a lot of non-invasively acquired information about the myocardium. One of the sequences used is T1 mapping [1,2], which allows us to measure myocardial extracellular volume (ECV), using T1 relaxation time values acquired before and after the administration of a gadolinium contrast agent. However, haematocrit $(\mathrm{Htc})$ is related to the blood volume of distribution and is also required to calculate ECV. Higher ECV values have already proven to be a pathological finding in many cardiovascular diseases [2-12]. There are already studies showing a strong correlation between ECV measured by CMR and histological findings $[13,14]$.

Some authors have already published their findings and formulae in this field $[3,4,15-18]$ and as some other studies have already showed - the T1 relaxation times obtained while using Modified Look-Locker 
Imaging (MOLLI) sequences still show statistically significant differences between different types of scanners with the same field strength (both 1.5T and 3T) [19, 20]. In addition, as Treibel stated in his study [17], further comparisons and potentially a local calibration in every single centre for synthetic Htc and ECV calculations are required. While some other authors have used Shortened Modified Look-Locker Imaging (Sh-MOLLI) or Sh-MOLLI and MOLLI sequences $[15,17]$, exclusively MOLLI sequences have been used in our study. Other studies have also used different formulae for calculating synthetic Htc - with mostly the reciprocal proportion used $[3,4,16,17]$. To our knowledge, post-contrast values of a blood pool have never been added to the formula calculating synthetic Htc before.

This study could provide more evidence whether linear or reciprocal regression is to be used while calculating a synthetic Htc for synthetic ECV, if the formula obtained by using an Ingenia 1.5T scanner resembles any other obtained with a different scanner and if a statistically relevant improvement can be achieved by adding post-contrast values to the calculation.

\section{Methods:}

The aim of the study was to generate a formula to determine a synthetic Htc and ECV from the T1 blood relaxation times using MOLLI sequences obtained with an Ingenia 1.5T scanner and to determine whether linear or reciprocal regression is statistically more relevant to our data. Also, a correlation between Htc and T1 relaxation times using only native and both native and post-contrast values was aimed to be found. Formulae created were used for ECV quantification and compared with values acquired using different formulae and laboratory methods.

This retrospective study was composed of 139 subjects with a wide range of diagnoses, who underwent CMR examination in an Ingenia 1.5T scanner using both native and contrast methods. Inclusion criteria were having available both native and post-contrast T1 mapping sequences and a blood sample collected right before CMR examination (several minutes). The patients consisted of 5 groups following primary diagnoses: chronic obstructive pulmonary disease, Duchene muscular dystrophy female carriers, a group after anthracycline treatment, patients after a heart transplant, and controls. Control group included patients with a clinical indication for CMR examination, but normal CMR findings, other cardiac results and no other relevant medical history (Table 1). The appropriate size of the group to reveal even medium size effects was checked using the online available calculator for multiple regression [21], with parameters set as $f^{2}=0.15$, power level $(1-\beta)=0.8, \alpha=0.05$, and 3 predictors. The number of patients enrolled well exceeded the necessary minimum of $n=76$. 
Table 1

Characteristics of the patient groups included in the study.

\begin{tabular}{|c|c|c|c|c|c|c|}
\hline $\begin{array}{l}\text { Primary } \\
\text { diagnosis }\end{array}$ & $\begin{array}{l}\text { Number } \\
\text { of } \\
\text { patients }\end{array}$ & Age & Female & $\begin{array}{l}\text { Mean } \\
\text { laboratory } \\
\text { Htc }\end{array}$ & $\begin{array}{l}\text { Mean T1 } \\
\text { blood } \\
\text { relaxation } \\
\text { time - native }\end{array}$ & $\begin{array}{l}\text { Mean T1 blood } \\
\text { relaxation time - } \\
\text { post-contrast }\end{array}$ \\
\hline Overall & 139 & $\begin{array}{l}35,42 \\
\pm \\
15,97\end{array}$ & $\begin{array}{l}76 \\
(54,7 \\
\%)\end{array}$ & $\begin{array}{l}0,41 \pm \\
0,04\end{array}$ & $\begin{array}{l}1545,78 \pm \\
84,24\end{array}$ & $229,76 \pm 27,03$ \\
\hline DMD carriers & 40 & $\begin{array}{l}37,93 \\
\pm \\
11,85\end{array}$ & $\begin{array}{l}40 \\
(100 \\
\%)\end{array}$ & $0,4 \pm 0,03$ & $\begin{array}{l}1560,33 \pm \\
79,66\end{array}$ & $223,92 \pm 24,64$ \\
\hline $\begin{array}{l}\text { Patients after } \\
\text { anthracycline } \\
\text { treatment }\end{array}$ & 71 & $\begin{array}{l}25,99 \\
\pm 5\end{array}$ & $\begin{array}{l}26 \\
(36,6 \\
\%)\end{array}$ & $\begin{array}{l}0,42 \pm \\
0,04\end{array}$ & $1534 \pm 80,12$ & $230,9 \pm 29,02$ \\
\hline HT & 8 & $\begin{array}{l}53,63 \\
\pm \\
13,51\end{array}$ & $\begin{array}{l}2(25 \\
\%)\end{array}$ & $0,4 \pm 0,08$ & $\begin{array}{l}1563,5 \pm \\
104,27\end{array}$ & $234 \pm 26,46$ \\
\hline COPD & 15 & $\begin{array}{l}67,33 \\
\pm 8,5\end{array}$ & $\begin{array}{l}5(33,3 \\
\%)\end{array}$ & $\begin{array}{l}0,42 \pm \\
0,04\end{array}$ & $\begin{array}{l}1566,13 \pm \\
70,54\end{array}$ & $235,67 \pm 19,72$ \\
\hline Controls & 5 & $\begin{array}{l}24,4 \\
\pm 2,58\end{array}$ & $\begin{array}{l}3(60 \\
\%)\end{array}$ & $\begin{array}{l}0,44 \pm \\
0,04\end{array}$ & $1496,8 \pm 69,15$ & $235,8 \pm 24,21$ \\
\hline \multicolumn{7}{|c|}{ Values represent the number of patients or the median \pm standard deviation. } \\
\hline $\begin{array}{l}\text { Htc }=\text { haemat } \\
\text { transplant, } \mathrm{C}(\end{array}$ & $\begin{array}{l}\text { 1D carr } \\
\text { ronic c }\end{array}$ & $\begin{array}{l}\text { gen } \\
\text { ctiv }\end{array}$ & $\begin{array}{l}\text { carriers } \\
\text { monar }\end{array}$ & $\begin{array}{l}\text { Duchenne } \\
\text { sease. }\end{array}$ & cular dystro & $\mathrm{HT}=$ heart \\
\hline
\end{tabular}

Patients had their Htc measured using standard laboratory methods in a centralised hospital laboratory. Afterwards, the patients underwent CMR including T1 mapping using MOLLI sequences both before the administration of a contrast agent and 15 minutes after. Similarly as described previously [22] - a balanced single-shot T1-TFE sequence with an inversion prepulse, cardiac triggering and breath-hold technique in the mid-ventricular level in the short-axis was used. With a $5 \mathrm{~s}$ (3s) $3 \mathrm{~s} \mathrm{MOLLI} \mathrm{scheme} \mathrm{for}$ native T1 and 4s (1s) 3s (1s) 2s for enhanced T1 mapping was used with typical imaging parameters as follows: FOV $300 \times 300 \mathrm{~mm}$, reconstruction matrix 256, slice thickness $10 \mathrm{~mm}$, acquisition voxel size 2.00 $\times 2.00 \times 10.00 \mathrm{~mm}$, time to repetition $(T R) \approx 2.2 \mathrm{~ms}$, echo time $(T E) \approx 1.1 \mathrm{~ms}$, flip angle $35^{\circ}$, SENSE factor 2. For the contrast agent, gadolinium (Gadovist, Bayer AG, Leverkusen, Germany) in the dosage of $0.2 \mathrm{mmol} / \mathrm{kg}$ was used.

The regions of interest (ROIs) were contoured in both native and post-contrast images, including only a blood pool without any papillary muscles (Fig. 1, 2). First, the formula and correlation coefficient using only native values of the blood pool was calculated; afterwards, the same calculation was performed using both native and post-contrast values. Acquired Htc values were used to quantify ECV. 
As for statistical analysis - Pearson correlation coefficients and related p-values were computed to assess the correlation between Htc and CMR-derived blood native and blood enhanced values. Four regression models to estimate Htc from blood native and blood post-contrast values were created in the following fashion:

1) (native linear): $\mathrm{Htc}_{\mathrm{est}}=\mathrm{b}+\left(\mathrm{T}_{1-\mathrm{BN}} / \mathrm{a}\right)$

2) (native reciprocal): $\mathrm{Htc}_{\mathrm{est}}=\mathrm{b}+\left(\mathrm{a} / \mathrm{T}_{1-\mathrm{BN}}\right)$

3) (combined linear): $\mathrm{Htc}_{\mathrm{est}}=\mathrm{C}+\left(\mathrm{T}_{1-\mathrm{BN}} / \mathrm{a}\right)+\left(\mathrm{T}_{1-\mathrm{BP}} / \mathrm{b}\right)$

4) (combined reciprocal): $\mathrm{Htc}_{\mathrm{est}}=\mathrm{c}+\left(\mathrm{a} / \mathrm{T}_{1-\mathrm{BN}}\right)+\left(\mathrm{b} / \mathrm{T}_{1-\mathrm{BP}}\right)$

Where $\mathrm{Htc}_{\text {est }}$ is an estimated value of haematocrit, a, b, c are constants, $\mathrm{T}_{1-\mathrm{BN}}$ is a blood native value and $\mathrm{T}_{1-\mathrm{BP}}$ is a blood post-contrast (enhanced) value.

Further, using the estimated or measured Htc value, the extracellular volume was calculated as:

$\operatorname{ECV}=(1-\mathrm{HtC}) *\left(\left(\left(1 / \mathrm{T}_{1-\mathrm{MP}}\right)-\left(1 / \mathrm{T}_{1-\mathrm{MN}}\right)\right) /\left(\left(1 / \mathrm{T}_{1-\mathrm{BP}}\right)-\left(1 / \mathrm{T}_{1-\mathrm{BN}}\right)\right)\right.$

Where $T_{1-M N}$ is a myocardium native value and $T_{1-M P}$ is a myocardium post-contrast value. The ECV calculated using either measured or estimated $\mathrm{Htc}$ was compared to the values based on linear and reciprocal models by Treibel et al. using blood native values obtained by MOLLI and ShMOLLI (Treibel et al. 2015; 2016) and Bland-Altman analysis was performed to assess the systematic bias.

The statistical significance of these factors was assessed. To compare the linear and reciprocal models, a coefficient of determination $\left(r^{2}\right)$ was attributed to each model. A residual analysis was employed to confirm the adequacy of each model for the estimation of $\mathrm{Htc}$ and the residual variance of the model with the highest $r^{2}$ was compared with other models using an F-test.

Finally, as the study group was heterogeneous and consisted of patients suffering from several diagnoses, the possible effect of the primary diagnosis was determined using an Analysis of Covariance (ANCOVA), with the primary diagnosis as an independent factor in the model.

Normality was tested by Kolmogorov-Smirnov test of normality and by visual inspection of histograms. To exclude substantial multicollinearity between the variables used in a model, the variance inflation factor (VIF) was computed for a model containing blood native value as an independent and blood postcontrast value as a dependent variable, as well as for the diagnoses (nominal data, one binary variable 
per each diagnosis, independent) and the blood native / blood post contrast value (dependent variable). Value $>2.5$ was considered as a substantial multicollinearity.

Generally, results with $\mathrm{P}<0.05$ were regarded as statistically significant. The analysis was performed using STATISTICA 13.2 (TIBCO software, The United States of America).

\section{Results:}

The blood native value showed a moderately strong negative correlation with $\mathrm{Htc},(r=-0.68, \mathrm{P}<0.001)$ (Fig. 3), while using only the blood post-contrast value showed only a mildly positive correlation, which lacked statistical significance $(r=0.15, P=0.09)$ (Fig. 4). These two CMR-derived parameters were not correlated between themselves $(r=-0.02, P=0.81)$. The value of VIF was very small (1.0004), effectively excluding any collinearity. The parameters were thus regarded as independent. The $p$-value of Kolmogorov-Smirnov test was $>0.10$ for all measured parameters in CMR, as well as for Htc value, and the histograms corresponded with the Gaussian distribution in all cases.

Using native and post-contrast blood pool values, the following formulae were created:

1) "Htc ${ }_{\text {est }}=0.914-\left(\mathrm{T}_{1-\mathrm{BN}} / 3051\right)$ ", where the blood native value significantly contributed to the estimation $(P<0.001)$

2) "Htc $\mathrm{est}_{\mathrm{e}}=-0.098+\left(779 / \mathrm{T}_{1-\mathrm{BN}}\right)$ ", where the blood native value significantly contributed to the estimation $(P<0.001)$

3) "Htc est $=0.870-\left(\mathrm{T}_{1-\mathrm{BN}} / 3061\right)+\left(\right.$ blood post-contrast $\left.\mathrm{T}_{1-\mathrm{BP}} / 5392\right)$ ", where both factors significantly contributed to the Htc estimation $\left(T_{1-B N}: P<0.001, T_{1-B P}: P=0.043\right)$.

4) "Htc $\mathrm{est}=-0.047+\left(779 /\left(\mathrm{T}_{1-\mathrm{BN}}\right)\right)-\left(11.36 / \mathrm{T}_{1}-\mathrm{BP}\right)$ ", where both factors significantly contributed to the Htc estimation $\left(T_{1-B N}: P<0.001, T_{1-B P}: P=0.022\right)$.

The highest coefficient of determination (0.49) was observed in the combined reciprocal model (4), followed by 0.48 for the combined linear model (3) and 0.47 for both models using native values only (models 2 and 1). Correspondingly, the variance of residuals decreased from model 1 to model 4 , as there was no statistically significant difference in the variance of residuals ( $P>0.05$ in all cases).

The descriptive statistics of ECV values obtained by different methods is shown in Table 2. 
Table 2

ECV values obtained by different methods of haematocrit estimation

\begin{tabular}{|c|c|c|c|c|c|}
\hline $\begin{array}{l}\text { Method of } \\
\text { haematocrit } \\
\text { estimation }\end{array}$ & $\begin{array}{l}\text { ECV } \\
\text { value }\end{array}$ & $\begin{array}{l}\text { ECV bias } \\
(95 \% \mathrm{Cl}) \\
{[\%] *}\end{array}$ & $\begin{array}{l}\text { Correlation } \\
\text { mean vs. bias } \\
(r)\end{array}$ & $\begin{array}{l}\text { Correlation mean } \\
\text { vs. bias ( } p \text {-value) }\end{array}$ & $\begin{array}{l}\mathrm{r}^{2} \text { in } \\
\text { haematocrit } \\
\text { estimation * }\end{array}$ \\
\hline $\begin{array}{l}\text { Direct } \\
\text { measurement }\end{array}$ & $\begin{array}{l}0.250 \\
\pm \\
0.035\end{array}$ & - & - & - & - \\
\hline $\begin{array}{l}\text { Native linear } \\
\text { (model 1) }\end{array}$ & $\begin{array}{l}0.250 \\
\pm \\
0.035\end{array}$ & $\begin{array}{l}0.2(-0.7- \\
1.1) \%\end{array}$ & 0.03 & 0.74 & 0.47 \\
\hline $\begin{array}{l}\text { Native reciprocal } \\
\text { (model 2) }\end{array}$ & $\begin{array}{l}0.250 \\
\pm \\
0.035\end{array}$ & $\begin{array}{l}0.2(-0.7- \\
1.1) \%\end{array}$ & 0.03 & 0.73 & 0.47 \\
\hline $\begin{array}{l}\text { Combined linear } \\
\text { (model 3) }\end{array}$ & $\begin{array}{l}0.250 \\
\pm \\
0.034\end{array}$ & $\begin{array}{l}0.2(-0.7- \\
1.0) \%\end{array}$ & -0.02 & 0.78 & 0.48 \\
\hline $\begin{array}{l}\text { Combined } \\
\text { reciprocal (model } \\
\text { 4) }\end{array}$ & $\begin{array}{l}0.250 \\
\pm \\
0.034\end{array}$ & $\begin{array}{l}0.2(-0.7- \\
1.0) \%\end{array}$ & -0.03 & 0.73 & 0.49 \\
\hline $\begin{array}{l}\text { Treibel et al. } \\
\text { linear MOLLI ** }\end{array}$ & $\begin{array}{l}0.238 \\
\pm \\
0.033\end{array}$ & $\begin{array}{l}-4.6 \%(-5.5 \\
--3.8) \%\end{array}$ & -0.13 & 0.13 & 0.47 \\
\hline $\begin{array}{l}\text { Treibel et al. } \\
\text { reciprocal MOLLI } \\
\star \star\end{array}$ & $\begin{array}{l}0.237 \\
\pm \\
0.034\end{array}$ & $\begin{array}{l}-5.2(-6.0- \\
-4.3) \%\end{array}$ & -0.03 & 0.74 & 0.47 \\
\hline $\begin{array}{l}\text { Treibel et al. } \\
\text { reciprocal } \\
\text { shMOLLI }\end{array}$ & $\begin{array}{l}0.252 \\
\pm \\
0.035\end{array}$ & $\begin{array}{l}0.8(-0.1- \\
1.6) \%\end{array}$ & 0.01 & 0.93 & 0.47 \\
\hline \multicolumn{6}{|c|}{ * Compared to the direct measurement of haematocrit value } \\
\hline \multicolumn{6}{|c|}{ ** Significant bias compared to values obtained by direct measurement of Htc } \\
\hline
\end{tabular}

Interestingly, when compared with Treibel's formulae, there was a significant bias in the case of MOLLIbased empirical formulae that rendered significantly lower results with around $5 \%$ bias in both cases, while there was no significant bias in the case of ShMOLLi-based formula (bias $<1 \%$; the $95 \%$ confidence interval involved zero). The bias was independent on the value of ECV in all cases ( $p$ for trend $>0.05$ ). As expected, the models based on our own data had negligible bias close to 0 .

Finally, the primary diagnosis was added to the models as an independent factor. The multicollinearity of primary diagnosis and either blood native (VIF $=1.09$ ) or blood post-contrast (VIF $=1.03)$ T1 values was negligible, confirming the appropriateness of the model. In neither case did the factor of primary 
diagnosis contribute to the Htc estimation ( $P>0.05$ in all cases). The formulae were thus applicable to the whole study population, regardless of the primary diagnosis status.

\section{Discussion:}

This study provides more information about synthetic Htc calculation from the $\mathrm{T} 1$ relaxation times of a blood pool acquired using T1 mapping sequences on 1,5T Ingenia scanner. Adding post-contrast values to the formula showed a mild, but statistically relevant improvement of the synthetic Htc calculation. The frequency of using synthetic ECV maps and thus calculating synthetic Htc values is increasing. This study brings evidence that by simply adding post-contrast values to the calculation formula a statistically relevant improvement of the assessment accuracy could be achieved and also implies that results assessed using reciprocal regression to $\mathrm{T} 1$ relaxation times of blood pool are statistically more accurate.

In other studies, most authors have used reciprocal regression to T1 relaxation times [3, 17], several others [4, 16] have used the formula from Treibel's 2016 article [17]. Only Treibel in his 2015 study [15] has used linear regression to T1 blood relaxation times. Previous studies have used only native T1 relaxation times, whereas in this study a post-contrast $\mathrm{T} 1$ relaxation times were added to the formulae, resulting in a mild, but statistically relevant improvement of the assessed synthetic Htc and therefore synthetic ECV accuracy.

This study was a single centre, which means there is a certain selection bias, however, this ensures similarity of the protocol, sequences and magnetic resonance machine used, where an Ingenia 1.5T scanner was exclusively used. To prove the formulae to be independent of the machine, mapping sequence and parameters used, still more studies need to be done.

Control group in this study consists of patients indicated to CMR examination but with negative results. Since patients showed symptoms they can't be considered as healthy, but since relaxation times from blood pool and not myocardium were used and we find ethically problematic applying contrast agent to healthy volunteers without any clinical outcome from CMR examination, no healthy controls were enrolled in this study. Also, study population did not include any subjects with extreme values of Htc, such as anaemic patients or patients with polycythaemia vera.

\section{Conclusion:}

After a careful statistical analysis, the linear and reciprocal formulae for non-invasive calculating of Htc were created, at first using only native blood pool values, afterwards using both native and post contrast values. With assessed synthetic Htc values ECV were quantified and compared with values calculated using other formulae and laboratory methods. The synthetic Htc and ECV quantification were best explained by a model using reciprocals of native and post contrast values: " $\mathrm{Htc}_{\mathrm{est}}=0.047+\left(779 /\left(\mathrm{T}_{1}\right.\right.$ $\mathrm{BN}))-\left(11.36 / \mathrm{T}_{1}-\mathrm{BP}\right){ }^{\prime \prime} ; \mathrm{r}^{2}=0.49$. Adding post-contrast values to the formula proved to be statistically significant. A residual analysis showed a normal distribution of residuals, confirming the adequacy of our 
formulae. The formulae statistically proved to be applicable to the whole study population, regardless of the primary diagnosis.

In terms of ECV itself, the models based on our own data had negligible bias close to 0 , while using Treibel's formulae, there was a significant bias in the case of MOLLI-based empirical formulae that rendered significantly lower results with around $5 \%$ bias in both cases, but significantly lower bias in the case of ShMOLLi-based formula. This further implies statement Treibel made in his study [17], that potentially a local calibration in every single centre for synthetic Htc and ECV calculations are required.

\section{Declarations}

\section{Ethics Approval}

This retrospective study was performed in accordance with the Declaration of Helsinki (2000) of the World Medical Association. The Ethics Committee of the Faculty of Medicine, Masaryk University, confirmed under reference number 21052020 , that this study has been performed on data of patients already participating in other research studies with signed written consent about using their data anonymously for research purposes and therefore confirmed, that according to the Czech legislation, no specific new approval of the ethics committee was required.

\section{Consent to Participate}

Only participants who signed written consent about using their data anonymously for research purposes were enrolled in the study. No patient from potentially vulnerable group was enrolled in the study.

\section{Consent to Publication}

Not applicable.

\section{Conflict of Interest Statement}

The authors have no conflicts of interest to declare.

\section{Availability of data and materials}

The datasets used during the current study are available from the corresponding author on reasonable request.

\section{Funding Sources}


The work was supported by project no. LQ1605 from the National Program of Sustainability II (MEYS CR) and Masaryk university project "New trends in diagnostics and therapy of cardiomyopathies" number MUNI/A/1685/2020 with the support of the Specific University Research Grant, as provided by the Ministry of Education, Youth and Sports of the Czech Republic in the year 2021.

\section{Author Contributions}

LO, RP, and LS were the main designers of this study. LO was the major contributor in writing the manuscript. JM performed the statistical analysis. LM, RP and VK contributed to the patient recruitment and inclusion. VF and TH performed CMR examinations and with $\mathrm{LO}$ and $\mathrm{MH}$ performed the data analysis. All authors read and approved the final manuscript.

\section{Acknowledgments}

Not applicable.

\section{References}

1. Pennell DJ. Cardiovascular magnetic resonance: twenty-first century solutions in cardiology. Clin Med. 2003;3(3):273-278. doi:7861/clinmedicine.3-3-273

2. Ugander M, Oki AJ, Hsu L-Y, Kellman P, Greiser A, Aletras AH, Sibley CT, et al. Extracellular volume imaging by magnetic resonance imaging provides insights into overt and sub-clinical myocardial pathology. Eur Heart J. 2012;33(10):1268-1278. doi:1093/eurheartj/ehr481

3. Kammerlander AA, Duca F, Binder C, Aschauer S, Zotter-Tufaro C, Koschutnik M, et al. Extracellular volume quantification by cardiac magnetic resonance imaging without hematocrit sampling. Wien Klin Wochenschr. 2018;130(5):190-196. doi:1007/s00508-017-1267-y

4. Raucci FJ, Parra DA, Christensen JT, Hernandez LE, Markham LW, Xu M, Slaughter JC \& Soslow JH. Synthetic hematocrit derived from the longitudinal relaxation of blood can lead to clinically significant errors in measurement of extracellular volume fraction in pediatric and young adult patients. J Cardiovasc Magn Reson. 2017;19(1):58. doi:1186/s12968-017-0377-z

5. Puntmann VO, Voigt T, Chen Z, Mayr M, Karim R, Rhode K, et al. Native T1 mapping in differentiation of normal myocardium from diffuse disease in hypertrophic and dilated cardiomyopathy. JACC Cardiovasc Imaging. 2013;6(4):475-484. doi:1016/j.jcmg.2012.08.019

6. Soslow JH, Damon SM, Crum K, Lawson MA, Slaughter JC, Xu M, et al. Increased myocardial native $\mathrm{T} 1$ and extracellular volume in patients with Duchenne muscular dystrophy. $J$ Cardiovasc Magn Reson. 2016;18. doi:1186/s12968-016-0224-7

7. Soslow JH, Damon BM, Saville BR, Lu Z, Burnette B, Lawson MA, et al. Evaluation of post-contrast myocardial t 1 in duchenne muscular dystrophy using cardiac magnetic resonance imaging. Pediatr Cardiol. 2015;36(1):49-56. doi:1007/s00246-014-0963-x 
8. Piechnik SK, Ferreira VM, Lewandowski AJ, Ntusi NAB, Banerjee R, Holloway C, et al. Normal variation of magnetic resonance T1 relaxation times in the human population at 1.5 T using ShMOLLI. $J$ Cardiovasc Magn Reson. 2013;15:13. doi:1186/1532-429X-15-13

9. Moon JC, Messroghli DR, Kellman P, Piechnik SK, Robson MD, Ugander M, et al. Myocardial T1 mapping and extracellular volume quantification: a Society for Cardiovascular Magnetic Resonance (SCMR) and CMR Working Group of the European Society of Cardiology consensus statement. J Cardiovasc Magn Reson. 2013;15:92. doi:1186/1532-429X-15-92

10. Wong TC, Piehler K, Meier CG, Testa SM, Klock AM, Aneizi AA, et al. Association between extracellular matrix expansion quantified by cardiovascular magnetic resonance and short-term mortality. Circulation. 2012;126(10):1206-1216. doi:1161/CIRCULATIONAHA.111.089409

11. Wong TC, Piehler KM, Kang IA, Kadakkai A, Kellman P, Schwartzman DS, Mulukutla SR, et al. Myocardial extracellular volume fraction quantified by cardiovascular magnetic resonance is increased in diabetes and associated with mortality and incident heart failure admission. Eur Heart J. 2014;35(10):657-664. doi:1093/eurheartj/eht193

12. Sado DM, Flett AS, Banypersad SM, White SK, Maestrini V, Quarta G, et al. Cardiovascular magnetic resonance measurement of myocardial extracellular volume in health and disease. Heart. 2012;98(19):1436-1441. doi:1136/heartjnl-2012-302346

13. Fontana M, White SK, Banypersad SM, Sado DM, Maestrini V, Flett AS, et al. Comparison of T1 mapping techniques for ECV quantification. Histological validation and reproducibility of ShMOLLI versus multibreath-hold T1 quantification equilibrium contrast CMR. J Cardiovasc Magn Reson. 2012;14:88. doi:1186/1532-429X-14-88

14. Park SJ, Cho SW, Kim SM, Ahn, J, Carriere K, Jeong DS, et al. Assessment of Myocardial Fibrosis Using Multimodality Imaging in Severe Aortic Stenosis: Comparison With Histologic Fibrosis. JACC Cardiovasc Imaging. 2019;12(1):109-119. doi:1016/j.jcmg.2018.05.028

15. Treibel TA, Nasis A, Fontana M, Maestrini V, Castelletti S, Bhuva AN, et al. An instantaneous ECV with no blood sampling: using native blood T1 for hematocrit is as good as standard ECV. J CardiovasC Magn Reson. 2015;17(1):Q129. doi:1186/1532-429X-17-S1-Q129

16. Robison S, Karur GR, Wald RM, Thavendiranathan P, Crean AM, Hanneman K. Noninvasive hematocrit assessment for cardiovascular magnetic resonance extracellular volume quantification using a point-of-care device and synthetic derivation. J Cardiovasc Magn Reson. 2018;20(1):19. doi:1186/s12968-018-0443-1

17. Treibel TA, Fontana M, Maestrini V, Castelletti S, Rosmini S, Simpson J, et al. Automatic Measurement of the Myocardial Interstitium: Synthetic Extracellular Volume Quantification Without Hematocrit Sampling. JACC: Cardiovascular Imaging. 2016;9(1):54-63. doi:1016/j.jcmg.2015.11.008

18. Treibel T, Fontana M, Maestrini V, Castelletti S, Rosmini S, Simpson J, et al. Synthetic ECV simplifying ECV quantification by deriving haematocrit from T1 blood. Heart 2015;101:A16-A17. 
19. Lee Y, Callaghan MF, Acosta-Cabronero J, Lutti A, Nagy Z. Establishing intra- and inter-vendor reproducibility of T1 relaxation time measurements with 3T MRI. Magn Reson Med. 2019;81(1):454465. doi:1002/mrm. 27421

20. Raman FS, Kawel-Boehm N, Gai N, Freed M, Han J, Liu CY, et al. Modified look-locker inversion recovery $\mathrm{T} 1$ mapping indices: assessment of accuracy and reproducibility between magnetic resonance scanners. J Cardiovasc Magn Reson. 2013;15:64. doi:1186/1532-429X-15-64

21. Free Statistics Calculators - Home. https://www.danielsoper.com/statcalc/default.aspx. Accessed October 17, 2019.

22. Panovský R, Pešl M, Holeček T, Máchal J, Feitová V, Mrázová L, et al. Cardiac profile of the Czech population of Duchenne muscular dystrophy patients: a cardiovascular magnetic resonance study with T1 mapping. Orphanet J Rare Dis. 2019;14(1):10. doi:1186/s13023-018-0986-0

\section{Figures}

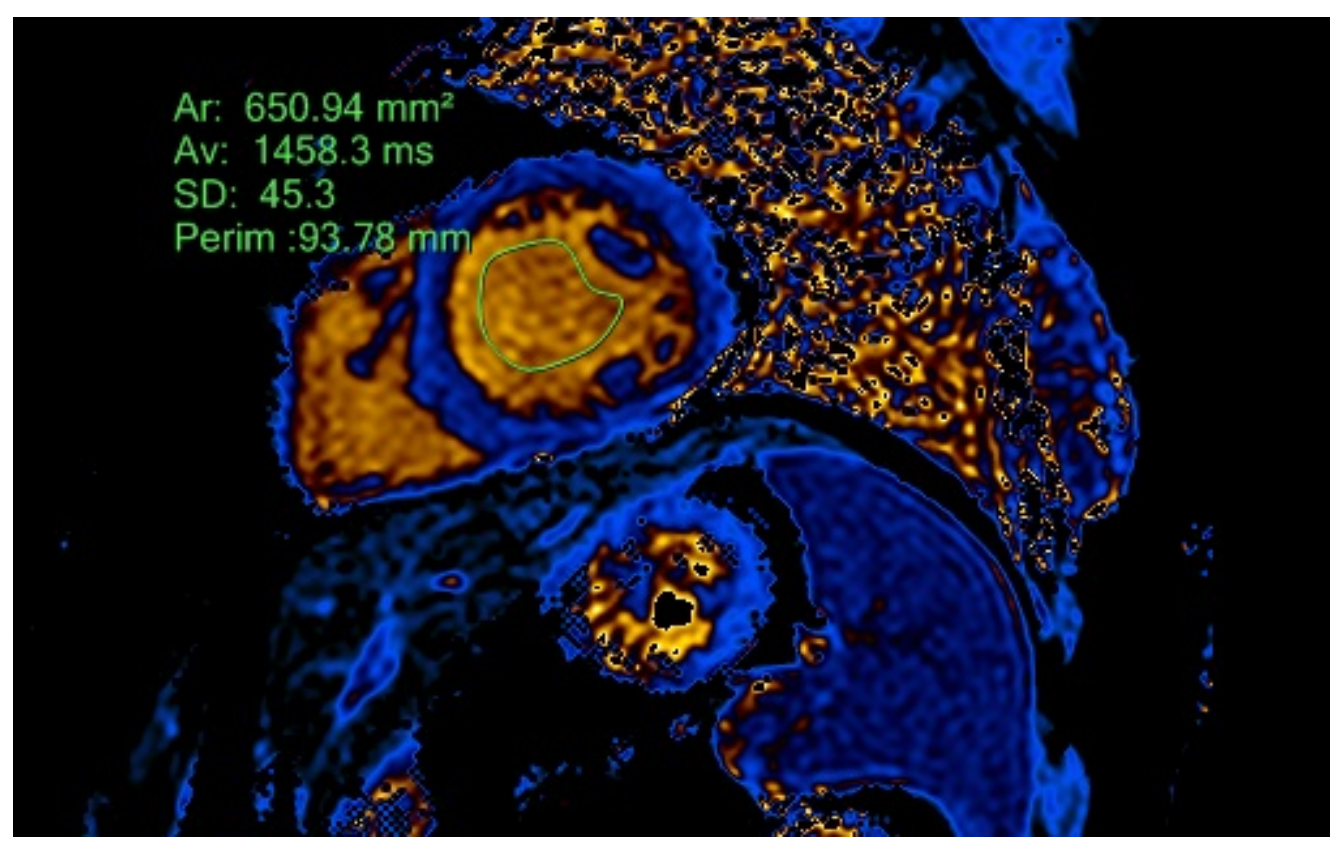

\section{Figure 1}

Measurement of $\mathrm{T} 1 \mathrm{blood}$ relaxation time in a native T1 mapping image. 


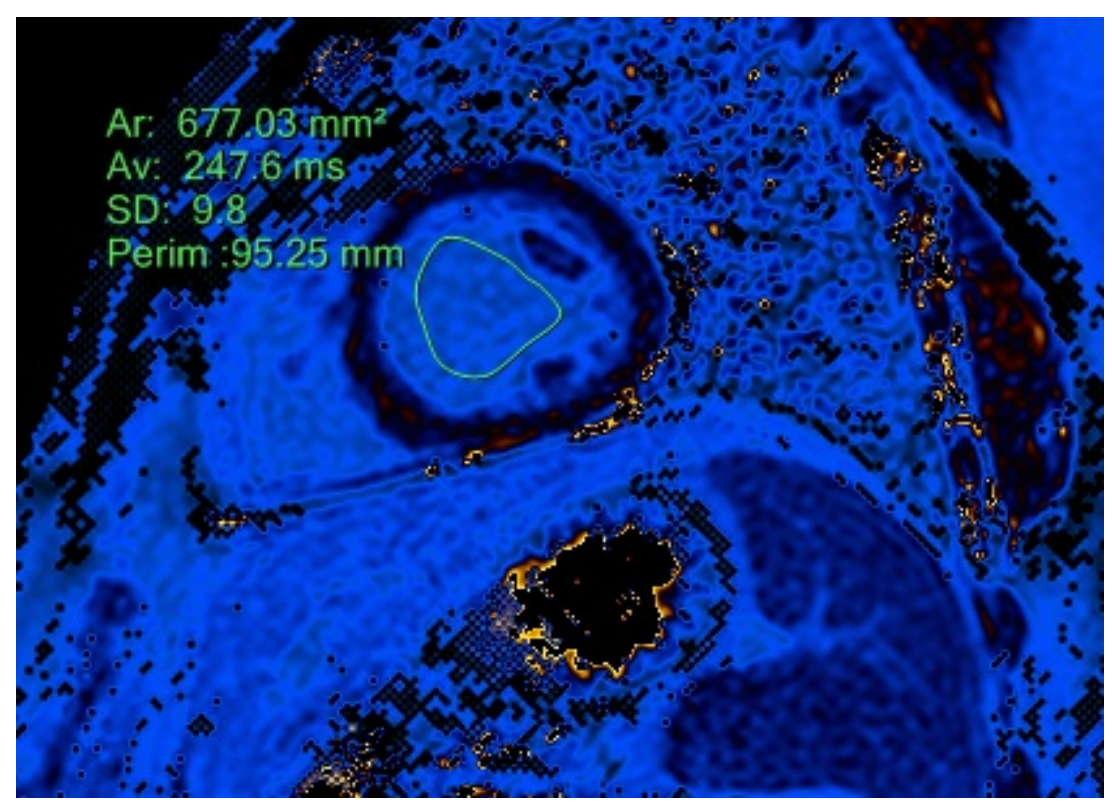

Figure 2

Measurement of T1 blood relaxation time in a postcontrast T1 mapping image.

Scatterplot: hematocrit vs. blood native

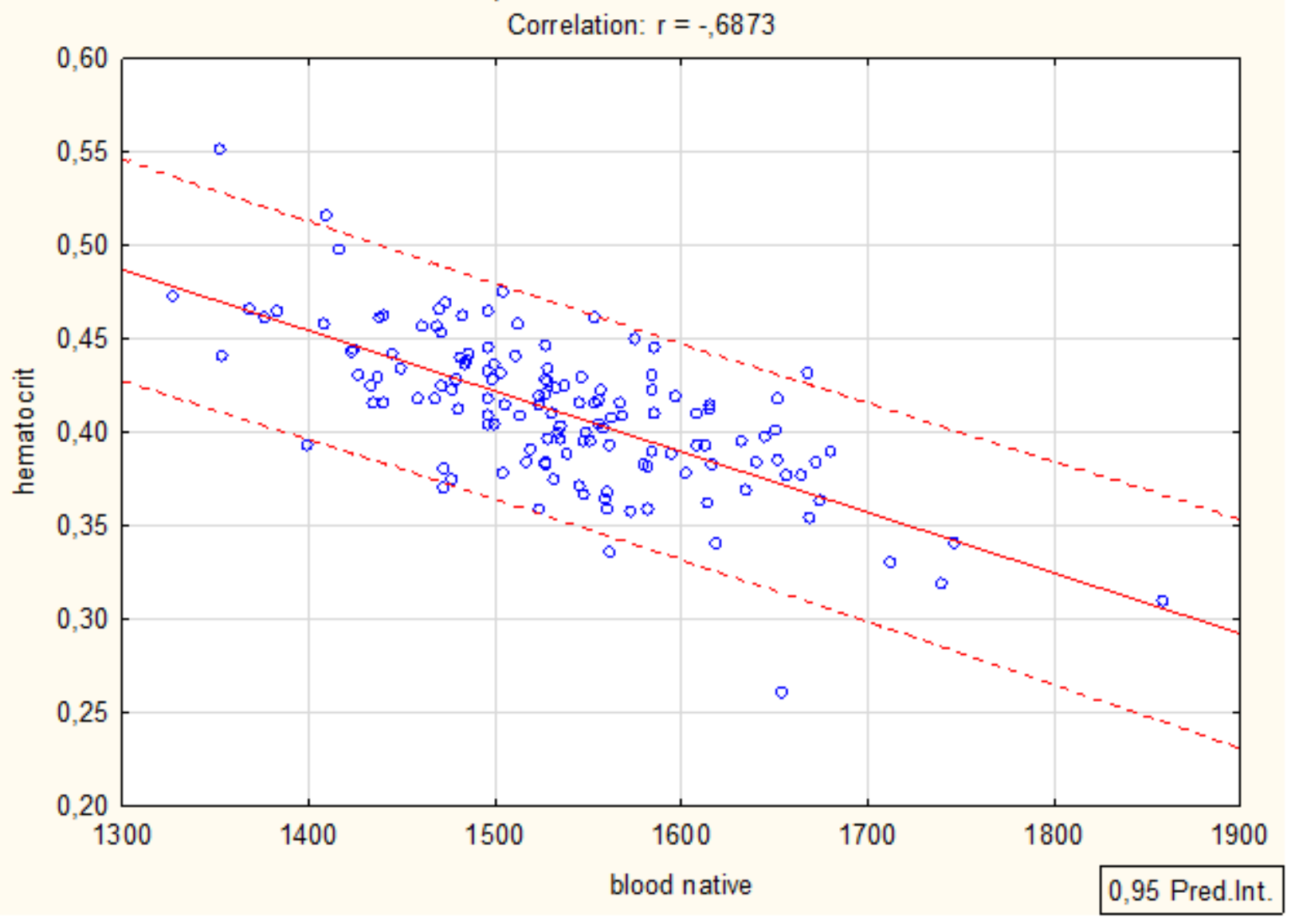

Figure 3 
Scatter plot showing the correlation between laboratory measured Htc and native $\mathrm{T} 1 \mathrm{blood}$ relaxation time.

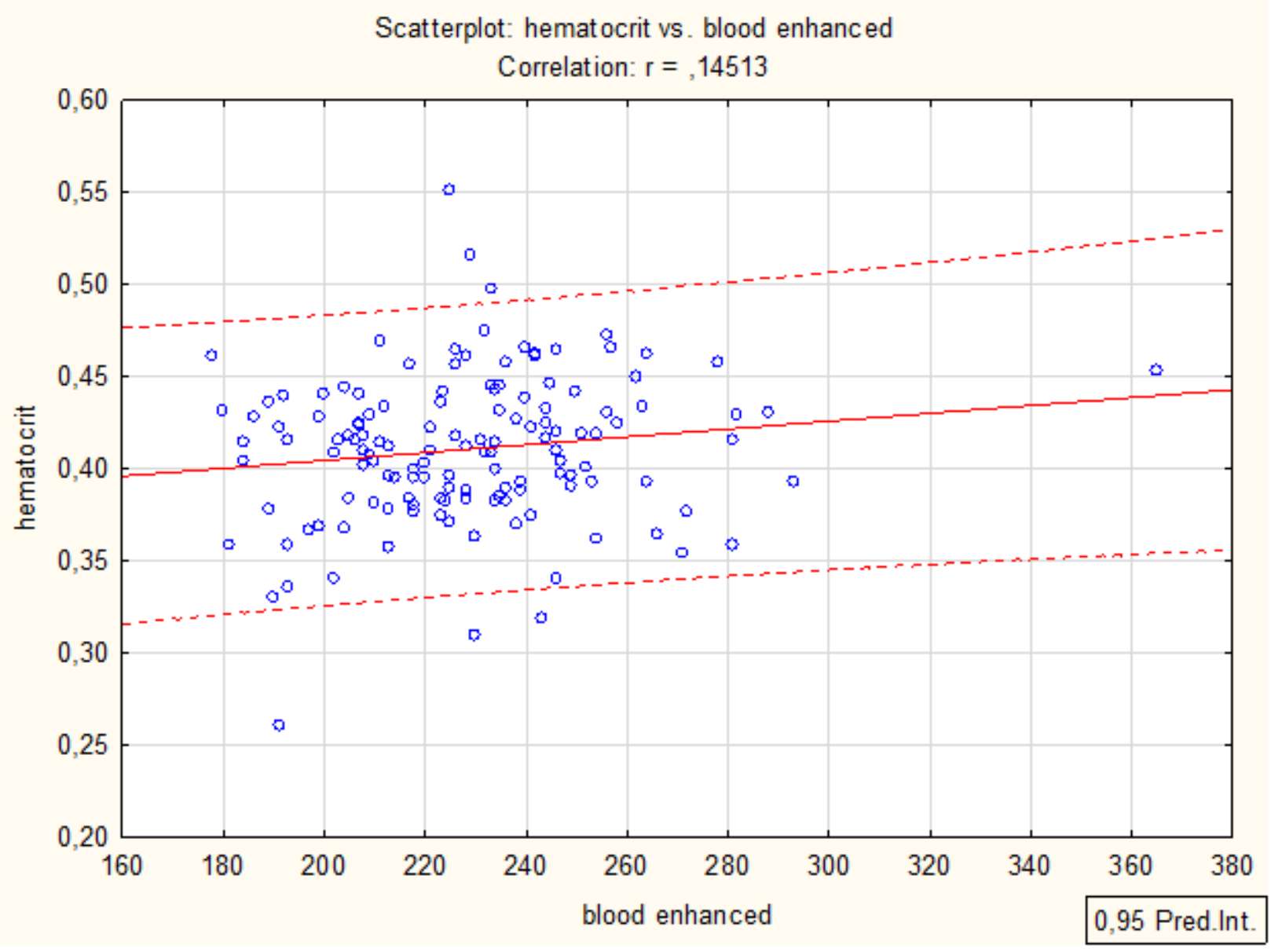

\section{Figure 4}

Scatter plot showing the correlation between laboratory measured Htc and post-contrast $\mathrm{T} 1$ blood relaxation time. 